\title{
Traumatic spinal cord injury complicating ankylosing spondylitis
}

\author{
N Ticó ${ }^{1}$, S Ramon ${ }^{1}$, F Garcia-Ortun ${ }^{1}$, L Ramirez ${ }^{1}$, T Castelló ${ }^{1}$, L Garcia-Fernandez ${ }^{1}$ and E Lience ${ }^{2}$ \\ ${ }^{1}$ Spinal Injury Unit, Traumatology and Rehabilitation University Hospital, Ciutat Sanitària Universitària Vall \\ d'Hebron, Psg. Vall d'Hebron 119-129, 08035 Barcelona; ${ }^{2}$ Rheumatology Service, Ciutat Sanitària Universitària Vall \\ d'Hebron, Spain
}

\begin{abstract}
The aim of this paper is to review the incidence and characteristics found in traumatic spinal cord injury (SCI) occurring in patients with long-standing ankylosing spondylitis (AS). The incidence of patients with traumatic SCI admitted to our unit from January 1984 to February 1996 was $2 \%$ (15 out of 893). They were all men with a mean age of 56 years. Most frequently the etiology of the lesion was a motor vehicle accident and the injury was mainly due to a hyperextension mechanism. Acute spinal fracture occurred in 13 patients, all involving the cervical region. No fracture was observed in two patients with thoracic neurological level. Three patients presented with an interval free period of neurological symptoms in whom a spinal epidural hematoma was visualized with magnetic resonance imaging. On admission eight patients were diagnosed as having complete SCI and the other seven an incomplete SCI. In the acute phase, respiratory complications were most frequent, causing six patients to die. Treatment was conservative in 14 patients. Multidisciplinary management of these patients should be implemented in an institution equipped with both a Spinal Injury Unit and an Intensive Care Unit.
\end{abstract}

Keywords: ankylosing spondylitis; traumatic spinal cord injury; spine fracture; spinal epidural hematoma

\section{Introduction}

Ankylosing spondylitis (AS) is an inflammatory disease involving the axial spine. ${ }^{1}$ Vertebral biomechanics are altered thus rendering the spine prone to trauma which, even though minimal, may cause serious neurological lesions, particularly in patients with long term AS and a completely ankylosed spine. ${ }^{2}$ Traumatic vertebral fractures are a serious complication of AS; they are highly unstable and are frequently associated with a neurological lesion. The mortality rate is high, ranging from $35-50 \%{ }^{3-5}$

It is not uncommon to find a free interval between the trauma and the onset of the neurological clinical signs or neurological deterioration in established spinal cord injury (SCI). In both situations a spinal epidural hematoma (SEH) must be ruled out. ${ }^{3}$ The reported incidence of $\mathrm{SEH}$ in these patients after trauma ranges from $10-50 \% .^{3,5-7}$

The aim of this paper is to review the incidence and characteristics of acute traumatic SCI in patients with AS in our hospital in order to assess the morbidity, mortality and the functional status in these patients.

Correspondence: LG Fernández

\section{Materials and methods}

We have made a retrospective study of patients with acute traumatic SCI associated with AS admitted in the Spinal Injury Unit (SIU) of the Rehabilitation Department at the University Hospital Vall d'Hebron, from January 1984 to February 1996. An AS diagnosis was reached for each case according to the modified New York criteria.,

For this study the variables were: demographic data: age, sex; years of evolution of AS; trauma related data: etiology, mechanism of injury as determined by clinical history and radiological findings; location and type of vertebral fracture; neurological lesion with or without free interval, SCI type according to the American Spinal Injury Association (ASIA) scale ${ }^{10}$ and neurological deterioration; magnetic resonance imaging (MRI): pattern of the spinal cord injury, SEH; treatment: conservative or surgical; complications and mortality; functional status at present: ambulation and work status.

\section{Results}

Of 893 patients who were hospitalized in the SIU for acute traumatic SCI during the past 12 years, 15 had AS. This represents an incidence of $2 \%$. They were all men with a mean age of 56 years (range $31-80$ ). The average follow-up time was 10.2 months (range 1 day- 
27 months). The mean evolution from the diagnosis of AS was 25 years (range 7-50).

The most frequent etiology of the SCI was a motor vehicle accident in 11 patients, accidental fall in three and blow by a bale of straw in the cervical region in one. Thirteen of the 15 patients $(87 \%)$ had an acute vertebral fracture which was not located in a spontaneous pseudoarthroses area. The most common type vertebral column lesion was fracture-dislocation. In the other two patients $(13 \%)$ there was no fracture or pseudoarthroses (Table 1). The mechanism of fracture was hyperextension in nine patients $(60 \%)$ and flexion in four $(40 \%)$. All the fractures were cervical, involving the lower cervical C5-C7 segment in 10 patients, and the $\mathrm{C} 4-\mathrm{C} 5$ segment in two. One patient had a fracture of the $\mathrm{C} 2-\mathrm{C} 6$ spinous processes.

On admission, eight patients $(53 \%)$ presented with a complete SCI and the other seven $(47 \%)$ had an incomplete SCI. The neurological level was cervical in 13 patients and thoracic in two. In three patients there was an interval free of neurological involvement, lasting half an hour, $2 \mathrm{~h}$ and $48 \mathrm{~h}$ respectively (Table
2). In the remaining 12 patients the onset of the neurological abnormalities was noted at the time of the trauma. One of these 12 patients presented neurological deterioration, he was a diabetic, eightyyear-old man with an incomplete C4 SCI, ASIA C, from $\mathrm{C} 5-\mathrm{C} 6$ fracture-dislocation. He was intubated and had mechanical ventilation on admission into our Intensive Care Unit (ICU), nevertheless progression to complete C4 SCI, ASIA A took place and the patient died within 13 days.

MRI could be performed in only five patients in the acute phase. It was impossible to perform it in the others because of their poor clinical condition. MRI disclosed spinal cord hemorrhage in one patient, a pattern of cord contusion in one other, and $\mathrm{SEH}$ in the three patients who had a free interval. None of the three patients with a SEH underwent surgical treatment.

The only patient who was surgically treated was a 31-year-old man with an incomplete C7 SCI, ASIA B, from $\mathrm{C} 6-\mathrm{C} 7$ fracture-dislocation secondary to direct trauma of his neck by a bale of straw. He was operated on because of the failure of fracture

Table 1 Summary of patients

\begin{tabular}{|c|c|c|c|c|c|c|}
\hline Case \# & Etiology & $\begin{array}{l}\text { Mechanism } \\
\text { of injury }\end{array}$ & Fracture type & $\begin{array}{l}\text { Fracture } \\
\text { location }\end{array}$ & $N L$ & $\begin{array}{l}A S I A \\
A / D / F\end{array}$ \\
\hline 1 & MVA & Extension & Spinous processes & $\mathrm{C} 5-\mathrm{C} 7$ & $\mathrm{C} 8$ & $\mathrm{C} / \mathrm{C} / * *$ \\
\hline 2 & MVA & Extension & Fr-disl & $\mathrm{C} 6-\mathrm{C} 7$ & C6 & $\mathrm{A} / \mathrm{A} / \mathrm{A}$ \\
\hline 3 & Fall & Flexion & Subdisl & $\mathrm{C} 6-\mathrm{C} 7$ & $\mathrm{C} 7$ & $\mathrm{D} / \mathrm{E} / \mathrm{E}$ \\
\hline 4 & Blow & Flexion & Fr-disl & $\mathrm{C} 6-\mathrm{C} 7$ & $\mathrm{C} 7$ & $\mathrm{~B} / \mathrm{D} / \mathrm{D}$ \\
\hline 5 & MVA & Extension & Spinous processes & $\mathrm{C} 2-\mathrm{C} 6$ & C6 & $\mathrm{B} / \mathrm{B} / *$ \\
\hline 6 & MVA & Extension & Fr-disl & $\mathrm{C} 6-\mathrm{C} 7$ & C6 & $\mathrm{A} / \mathrm{A} / \mathrm{A}$ \\
\hline 7 & Fall & & No fracture & & $\mathrm{T} 2$ & $\mathrm{~A} / \mathrm{C} / * *$ \\
\hline 8 & Fall & Flexion & Fr-disl & $\mathrm{C} 6-\mathrm{C} 7$ & C6 & $\mathrm{A} / \mathrm{A} / *$ \\
\hline 9 & MVA & Extension & Fr-disl & $\mathrm{C} 4-\mathrm{C} 5$ & $\mathrm{C} 5$ & $\mathrm{C} / \mathrm{D} / \mathrm{D}$ \\
\hline 10 & MVA & Flexion & Fr-disl & $\mathrm{C} 6-\mathrm{C} 7$ & $\mathrm{C} 7$ & $\mathrm{~A} / \mathrm{A} / *$ \\
\hline 11 & MVA & & No fracture & & T9 & $\mathrm{C} / \mathrm{D} / \mathrm{E}$ \\
\hline 12 & MVA & Extension & C6 post arch & $\mathrm{C} 6-\mathrm{C} 7$ & C5 & $\mathrm{A} / \mathrm{A} / \mathrm{A}$ \\
\hline 13 & MVA & Extension & Fr-disl & C5 - C6 & C5 & $\mathrm{A} / \mathrm{A} / *$ \\
\hline 14 & MVA & Extension & Fr-disl & $\mathrm{C} 4-\mathrm{C} 5$ & $\mathrm{C} 4$ & $\mathrm{~A} / \mathrm{A} / *$ \\
\hline 15 & MVA & Extension & Fr-disl & C5-C6 & C5 & $\mathrm{C} / \mathrm{A} / *$ \\
\hline
\end{tabular}

Case \#: patient number; MVA: motor vehicle accident; NL: neurological level on admission; ASIA A/D/F: ASIA on admission/ discharge/follow-up; Fr-disl: fracture-dislocation; Subdisl: subdislocation; *: died during acute phase; **: died during chronic phase

Table 2 Description of patients that presented free interval

\begin{tabular}{lccccccc}
\hline Case \# & Age & Etiology & Free int. hours & Fracture type & ASIA $A / D / F$ & NL $A / D$ & MRI \\
\hline 7 & 71 & Fall & 2 & No fracture & A/C/** & T2/T5 & SEH T5-T10 \\
8 & 56 & Fall & 48 & Fr-disl C6-C7 & A/A/* & C6/C6 & SEH T1-T12 \\
& & & & No fracture & C/D $/ \mathrm{E}$ & T9/T9 & SEH C2-T3 \\
\hline
\end{tabular}

Case \#: patient number; MVA: motor vehicle accident; Free Int.: free interval; ASIA A/D/F: ASIA on admission/discharge/ follow-up; NL A/D: neurological level on admission/discharge; MRI: magnetic resonance imaging; SEH: spinal epidural hematoma; DH: disc herniation; Fr-disl: fracture-disclocation; *: died during acute phase; **: died during chronic phase 
reduction. Treatment was conservative in the remaining 14; two were treated with cervical traction followed by orthosis, and 10 with a rigid collar only; the other two patients with a thoracic neurological level and without a fracture were treated with a rigid thoraco-lumbar orthosis.

Eight patients were admitted directly to the ICU, seven of whom required mechanical ventilation followed by tracheostomy in six cases. The mean stay in the ICU was 20 days (range $1-45$ ). The most frequent complications in the acute phase were respiratory (Table 3 ).

Six patients $(40 \%)$ died in the acute phase of the lesion from respiratory problems. In the chronic phase, one patient died from chronic renal failure diagnosed prior to SCI and the other one from sepsis that originated in relation to epidural catheter for the treatment of spasticity (Table 4).

The functional status of the seven survivors at the last follow-up was as follows: of the three patients with a complete C6 SCI, ASIA A, one is working as a freelance worker in his own business, another is permanently disabled for work, and the third patient is retired. Both patients with an incomplete C7 SCI, ASIA D, can ambulate with the aid of one crutch and are permantly disabled for work. The two patients with an incomplete SCI, ASIA E are retired, one with a $\mathrm{C} 7$ lesion ambulates aidless and the other one with a T9 lesion ambulates with the aid of one crutch because of his spondylitic disease.

\section{Discussion}

The incidence of SCI in patients with AS has been described by various authors. Guttmann found only seven cases of AS in a review of 2500 patients with

Table 3 Main complications in the acute phase of the SCI

\begin{tabular}{lc}
\hline Complication & Number of patients \\
\hline Respiratory & 8 \\
Gastrointestinal hemorrhage & 4 \\
Postoperative esophago-cutaneus fistula & 1 \\
\hline
\end{tabular}

traumatic SCI $(0.28 \%))^{11}$ In Foo's series of 466 traumatic SCI cases, seven had AS $(1.5 \%)^{5}$ In our 12-year-long study of 893 patients with traumatic SCI, 15 presented AS which is proof of an incidence of $2 \%$.

In $\mathrm{AS}$ the progressive enchondral ossification associated with osteopenia resulted in the spine becoming rigid, fragile and a tube-like structure with poor resistance to stress and prone to fracture. ${ }^{4}$ The former factors may lead to serious neurological damage likely to occur following trauma even although this is mininal. ${ }^{2-5,12-14}$ Although falls are the most frequent cause of the SCI in AS, ${ }^{2,3,12,14}$ in our study motor vehicle accidents have been the most frequent.

According to most authors, neck hyperextension is the most frequent mechanism of SCI in AS. ${ }^{4-6,15,16}$ This could be the result of the vulnerability to falls found in these patients because of their progressive kyphotic positions. ${ }^{17}$ Hyperextension in patients with AS can result in fractures through the intervertebral disc, whereas a flexion injury mechanism causes fractures through the vertebral body. ${ }^{16}$ Rowed and Graham, amongst others, describe a tendency to displacement in these fractures, in which the ankylosed spine behaves as a long bone. ${ }^{2,3}$ Computed tomography is useful in the diagnosis of fractures that can be difficult to identify by conventional radiology. ${ }^{4}$ In the present study, all the vertebral fractures were found in the cervical spine. According to Hunter ${ }^{18} 75 \%$ of the spinal fractures are found in the cervical region and Hansen $^{19}$ found $14 \%$ of those in the thoracic region while only $5 \%$ occurred in the lumbar spine. Although fractures have been described at all cervical levels, in our study $77 \%$ of the fractures involved the C5-C7 segment which is similar to that described by Murray, for whom it was $74 \% .^{4}$ Fractures may be missed because the cervico-thoracic junction can be difficult to see on $\mathrm{X}$ rays, because ossified vertebral ligaments distort the normal anatomy and also because inflammatory disease is thought to be the cause of pain. ${ }^{4}$

The postraumatic SEH is commonly seen in patients with AS. SEH must be ruled out in cases of a free interval between the trauma and the onset of the neurological signs or a neurological deterioration of the SCI established. Our three patients with free interval showed a SEH on MRI.

Table 4 Description of patients that died

\begin{tabular}{lccccccc}
\hline Phase & Case \# & Age & NL & ASIA A/F & Death $T$ & Cause & $M V / T$ \\
\hline Acute & 5 & 47 & C6 & B/B & 1 day & Respiratory arrest & Respiratory sepsis \\
& 13 & 54 & C5 & A/A & 15 days & Respiratory sepsis & MV/T \\
& 8 & 56 & C6 & A/A & 1 month & Respiratory sepsis & $\mathrm{MV} / \mathrm{T}$ \\
& 10 & 67 & C7 & A/A & 2 months & Respiratory sepsis & $\mathrm{MV} / \mathrm{T}$ \\
& 14 & 74 & C4 & A/A & 24 days & Respiratory sepsis & $\mathrm{MV} / \mathrm{T}$ \\
Chronic & 15 & 80 & C5 & C/A & 13 days & Catheter sepsis & \\
& 1 & 52 & C8 & C/C & 2 years & Prelesional chronic renal failure & \\
\hline
\end{tabular}

Case \#: patient number; NL: neurological level on admission; ASIA A/F: ASIA on admission/follow-up; Death T: time of evolution at the moment of death; MV/T: mechanical ventilation/tracheotomy 
Spinal trauma increases the morbidity and mortality rates in patients with AS. Generally, vertebral fractures are highly unstable since they affect both the anterior and posterior columns of the spine which probably accounts for the high incidence of neurological complications and secondary mortality. ${ }^{4,7,12-14,18}$ Respiratory complications are frequent in SCI associated with AS as a result of a restrictive ventilatory alteration, especially in those with a high neurological level. ${ }^{4}$ All AS patients with SCI should therefore be admitted in the ICU in order to prevent or treat possible respiratory complications during the acute phase, and be transferred to the SIU only after their clinical condition is stabilized. In our study, mortality in the acute phase of the lesion reached $40 \%$, a percentage similar to that described by other authors for whom it ranged between 13 and $57 \% .^{2-}$ 5,16

Many authors preferred conservative treatment of the spinal fracture in these patients because of the high morbidity and mortality rates, especially respiratory complications associated with surgery. ${ }^{12,18}$ For them, surgery would be indicated in those patients who have neurological deterioration and after failure of fracture reduction with conservative treatment. ${ }^{2-4,6}$ Nowadays the spinal treatment recommended for these patients is internal fixation, because of advances in surgical techniques as can be done in the management in the ICU. This stabilization is the preferred method of treatment as it prevents prolonged bed rest and permits earlier rehabilitation above all in patients with SCI. ${ }^{20}$

To summarize, SCI in AS occurs in the lower region of the cervical spine as a result of a hyperextension mechanism occasionally associated with a SEH, mainly if there is a free interval or neurological deterioration of the SCI. The most frequent type of complication was respiratory. Multidisciplinary management of these patients should be implemented in an institution equipped with both a Spinal Injury Unit and an Intensive Care Unit to prevent the high morbility and mortality that is seen in these patients.

\section{Acknowledgements}

We thank Josep Graells for manuscript preparation and linguistic assessment, and to all of the health-care workers in the Spinal Injury Unit at Traumatology and Rehabilitation University Hospital Vall d'Hebron.

\section{References}

1 Westmark KD, Weissman BN. Complications of axial arthropaties. Orthop Clin North Am 1990; 21: $423-435$.

2 Graham B, Van Peteghem PK. Fractures of the spine in ankylosing spondylitis. Diagnosis, treatment and complications. Spine 1989; 14: $803-807$.

3 Rowed DW. Management of cervical spinal cord injury in ankylosing spondylitis: the intervertebral disc as a cause of cord compression. J Neurosurg 1992: 77: $241-246$.

4 Murray GC, Persellin RH. Cervical fracture complicating ankylosing spondylitis. A report of eight cases and review of the literature. Am J Med 1981; 70: 1033-1041.

5 Foo D, Sarkarati M, Marcelino V. Cervical spinal cord injury complicating ankylosing spondylitis. Paraplegia 1985; 23: $358-$ 633.

6 Garza-Mercado R. Traumatic extradural hematoma of the cervical spine. Neurosurgery 1989 24: $410-414$.

7 Bohlman HH, Ohio C. Acute fractures and dislocations of the cervical spine. An analysis of three hundred hospitalized patients and review of the literature. J Bone Joint Surg 1979; 61: 1119 1142 .

8 Van der Linden SM et al. Evaluation of diagnostic criteria for ankylosing spondylitis: a proposal for modification of the New York criteria. Arthritis Rheum 1984; 27: 361.

9 Goru T, Steven MM, Van der Linden S, et al. Evaluation of diagnostic criteria for ankylosing spondylitis: a comparison of the Rome, New York and modified New York criteria in patients with a positive clinical history screening test for ankylosing spondylitis. Br J Rheumatol 1985; 24: 242.

10 American Spinal Injury Association/International Medical Society of Paraplegia: International standards for Neurological and functional classification of spinal cord injury. Revised 1992. Chicago III: ASIA/IMSOP.

11 Guttmann L. Traumatic paraplegia and tetraplegia in ankylosing spondylitis. Paraplegia 1966; 4: $188-203$

12 Broom MJ, Raycroft JF. Complications of fractures of the cervical spine in ankylosing spondylitis. Spine 1988; 13: 763-766.

13 Fast A, Parikh S, Marin EL. Spine fractures in ankylosing spondylitis. Arch Phys Med Rehabil 1986; 67: 595-597.

14 Bradford DS, Pashman RS. Ankylosing spondylitis. In: Lonstein, Bradford, Winter, Ogilve, (eds.) Textbook of scoliosis and other spinal deformities. Moe's. 3rd Philadelphia: WB Saunders, $1995 ; 628-639$.

15 Raine GET. Fractures of the cervical spine in ankylosing spondylitis. Proc R Soc Med 1970; 63: 657-658.

16 Kewalramani LS, Taylor RG, Albrand OW. Cervical spine injury in patients with ankylosing spondylitis. J Trauma 1975; 15: 931 934.

17 Kaplan SL, Tun CG, Sarkarati M. Odontoid fracture complicating ankylosing spondylitis. A case report and review of the literature. Spine 1990; 15: 607-610.

18 Hunter T, Dubo H. Spinal fractures complicating ankylosing spondylitis. Ann Intern Med 1978; 88: $546-549$.

19 Hansen ST, Taylor TKF, Honet JC, Lewis FR. Fracturedislocations of the ankylosed thoracic spine in rheumatoid spondylitis. J Trauma 1967; 7: 827-837.

20 Kostuik JP. Ankylosing spondylitis: Surgical treatment. In: Frymoyer, Duker, Dadler, Kostuik, Weinstein, Whitecloud III, (eds) The adult spine principles and practice. Volume one. New York: Raven Press Ltd, 1991; 719-743. 